\title{
EL DESLINDE DE LA FRONTERA EN PIRINEOS CENTRALES (1857-1863) ${ }^{1}$
}

\author{
Joan Capdevila Subirana \\ Instituto Geográfico Nacional, 08002 - Barcelona \\ joan.capdevila.subirana@gmail.com
}

\begin{abstract}
Resumen: El deslinde formal de la frontera hispanofrancesa se llevó a cabo a mediados del siglo XIX, entre 1853 y 1868, y quedó plasmada en la serie de acuerdos internacionales conocida como Tratados de Límites de Bayona. El trabajo fue llevado a cabo por la Comisión Mixta de Límites que, desde el Cantábrico al Mediterráneo, definió 685 km de línea límite internacional y construyó 663 señales fronterizas. La línea resultante quiso atenerse al espíritu del Tratado de los Pirineos (1659) pero, sobretodo, solventar las diferentes problemáticas surgidas entre fronterizos, la mayoría relacionadas con aprovechamientos económicos del entorno. El tramo correspondiente a Pirineos Centrales, que corresponde a las provincias de Huesca y Lleida, fue objeto del Tratado de Límites de 1862 y el correspondiente Anexo con las actas de amojonamiento de 1863. En este artículo presentamos los trabajos de la Comisión Mixta de Límites, las negociaciones que tuvieron que llevar a cabo y la forma en como se resolvieron.
\end{abstract}

Palabras clave: frontera, deslinde, siglo XIX, Pirineos, pastos.

Abstract: The formal demarcation Spanish-French border took place in mid-
nineteenth century, between 1853 and 1868, and was reflected in the num-
ber of international agreements known as Border Treaties of Bayonne. The
work was carried out by the Joint Boundary Commission that, from the Bay
of Biscay to the Mediterranean, defined $685 \mathrm{~km}$ international boundary line
and built 663 border signs. The resulting line would follow the spirit of the

Recibido: 2-05-13. Aceptado: 17-10-13.

1. Este trabajo se ha realizado a partir de la tesis "La delimitació de la frontera hispanofrancesa (1659-1868)" defendida en la Universitat de Barcelona por el autor en 2012. Las fuentes se han obtenido del Archivo del Ministerio de Asuntos Exteriores y Cooperación (AMAEC), Madrid, y del Archive diplomatique du Ministère des Affaires Étrangères et Europénnes (AMEE), París. 
Treaty of the Pyrenees (1659) but, above all, solve the various problems arising from border, mostly related to economic exploitation of the environment. The Pyrénées tranche, which corresponds to the provinces of Huesca and Lleida, was the subject of the Boundary Treaty of 1862 and the corresponding Annex to the minutes of demarcation of 1863. In this paper we present the work of the Joint Boundary Commission, the negotiations had to be carried out as and how they were resolved.

Key words: border demarcation, nineteenth century, Pyrenees, pastures.

\section{Introducción}

La actual frontera en los Pirineos fue formalmente establecida con el Tratado de los Pirineos, ajustado en 1659 por Felipe IV por parte española y Luis XIV por parte francesa. Fue el punto final de una guerra larga, que durá más de dos décadas, como larga fue también la negociación que culminó en los 124 artículos del Tratado. La cuestión fronteriza estuvo muy presente en todo momento: Francia quiso rentabilizar las progresos territoriales conquistados durante la contienda y ya desde las primeras conversaciones se planteó la cesión española del Rosellón como condición para la paz. Para ello, el genio del cardenal Richelieu acuñó una fórmula breve y rotunda que permitió disimular el botín en un sólo artículo, el 42, donde se estableciía que “...los montes Pirineos, que habían dividido antiguamente las Galias de las Españas, harían también en adelante la división de estos dos mismos Reinos..."2. Así expresado, sin embargo, la elegancia no dejaba de esconder un alto grado de ambigüedad sobre cuales eran exactamente esos territorios que quedaban a uno y otro lado, por lo que en el mismo artículo se consideraba necesario que se reunieran comisarios por ambas partes para que "...declararan cuales son los Montes Pirineos (...) y señalaran los límites que han de tener”. Durante 1660 se mantuvieron varias reuniones con esta finalidad pero los resultados fueron escasos y contradictorios con lo que se pretendía aclarar. Si el artículo 42 parece referirse a la cresta o divisoria de aguas de la sierra como límite entre los dos reinos, el pacto alcanzado por Luis de Haro y el cardenal Mazarino a orillas del Bidasoa dejó el valle de la Cerdaña dividido por la mitad y con un enclave español, el municipio de Llívia, en suelo francés. Sin embargo, los dos primeros ministros dieron por terminada la discusión ante la premura del calendario que se habían impuesto para cumplir con todas las estipulaciones del Tratado.

El Tratado de los Pirineos fue uno de los primeros enmarcados dentro del nuevo orden internacional surgido a raíz de los Tratados de Westfalia, firmados once años atrás. Este nuevo orden se basó, entre otras cosas, en el concepto del estado nación sobe-

2. Las citas del Tratado de los Pirineos en lenguaje contemporáneo se han tomado de Usunáriz (2006). 
rano $^{3}$. La frontera fijada en 1659 fue, pues, la primera implantada en su sentido actual, es decir, el de límite del territorio sobre el que se ejerce la soberanía por parte del titular del poder máximo en ese territorio. Sin embargo, la falta de concreción sobre el terrempo de ese límite pronto empezó a plantear problemáticas al superponerse a los conflictos territoriales locales, lo que suele conocerse como relaciones de vecindad. La competencia por los recursos naturales, principal fuente de subsistencia para las comunidades pirenaicas, junto con la vaguedad del límite fronterizo provocó que muchos enfrentamientos, que se habrían podido considerar de índole privada y local, adquirieran tintes de conflicto internacional e involucraran a las cancillerías de Madrid y Paris.

La solución pasaba, como ha demostrado la práctica en la formalización de fronteras, por el deslinde preciso de la línea límite fronteriza: es decir, una delimitación concreta del trazado fronterizo, su posterior amojonamiento sobre el terreno y, finalmente, la adopción de las medidas necesarias para su mantenimiento. A lo largo del siglo XVIII y la primera mitad del XIX en el Pirineo se llevaron a cabo varios intentos de un trabajo como el descrito, pero sólo fructificaron unos pocos, muy acotados espacialmente: el acuerdo de 1750 por el que se deslinda la frontera en el río Reür (Puigcerdà, Girona); el convenio de 1764 por el que se deslinda la frontera alrededor de la fortaleza de Bellaguarda (La Jonquera, Girona) y el Tratado de Elizondo de 1785 por el se deslinda la frontera en Navarra. Los diversos fracasos cosechados en otras ocasiones demuestran lo complejo de este tipo de empresas.

Finalmente, el deslinde fue llevado a cabo por la Comisión Mixta de Límites, que se constituyó en 1853 con motivo del conflicto por los aprovechamientos madereros en Irati (Navarra). Formada por dos diplomáticos y dos militares y contando con amplia libertad para buscar soluciones a los diferentes problemas a los que tuvieran que hacer frente, la Comisión Mixta de Límites trabajó durante quince años para definir una línea fronteriza de $685 \mathrm{~km}$ y construir 663 señales fronterizas, plasmándolo en siete acuerdos internacionales. Como se puede adivinar, no fue una tarea fácil. La consecuencia más visible se halla en el trazado de la propia línea fronteriza. Su estudio topográfico (Capdevila, 2009, Anexo A) revela que la frontera discurre por la divisoria principal en sólo un 55\% de su longitud, mientras el resto transita por divisorias menores (14\%), está definida por poligonales (13\%), sigue la red fluvial (12\%) y un 6\% restante utiliza otros mecanismos (caminos, límites de propiedad y otros rasgos orográficos). La explicación se deduce del enfoque negociador con los fronterizos adoptado por la Comisión Mixta de Límites. El deslinde de la frontera, de hecho, fue el recurso utilizado por los gobiernos de ambos estados para solventar la conflictividad local en sus confines.

El trabajo de la Comisión Mixta de Límites ha sido tratado desde varios enfoques. El geógrafo Jean Sermet (1983) lo tuvo en cuenta en sus estudios sobre la relación en-

3. Para una discusión sobre la concepción jurisdiccional y territorial de la soberanía ver Sahlins (1993, 47). 
tre la frontera y el entorno pirenaico. El historiador Peter Sahlins (1993) lo consideró en su explicación sobre el desarrollo de las identidades nacionales en la Cerdaña. De forma más local, también se ha tratado su efecto en las relaciones de vecindad a ambos lados del Bidasoa (Fernández de Casadevante, 1985), su resolución de la conflictividad en la zona de Navarra (Arvizu, 2001) o, más recientemente, su actividad en Girona (Capdevila, 2012). Sin embargo, se hecha en falta un análisis parecido en la parte central de la cordillera, la zona de altas cumbres.

Dos de los acuerdos elaborados por la Comisión Mixta de Límites se refieren a los Pirineos Centrales, que en este caso coinciden con el límite correspondiente a las provincias de Huesca y Lleida. Se trata del Tratado de Límites de $1862^{4}$, en el que se delimita la línea, y sus Anejos de $1863^{5}$, donde se transcribe el acta de amojonamiento correspondiente. El trazado acordado, con la salvedad de la Val d'Aran, se ajusta a la divisoria principal, lo cual podría llevarnos a creer que aquí las fuentes de conflictividad fueron escasas. Sin embargo, no fue así, tal como puede deducirse de la lectura de los tratados. En este tramo, las decisiones adoptadas por la Comisión Mixta de Límites no se basan tanto en adecuar el trazado de la frontera sino en el deslinde de diferentes zonas en las que las partes implicadas pueden ejercer diferentes derechos (distintas modalidades de pastos, de refugio de ganado, de propiedad, de aprovechamiento maderero). Por lo tanto, para poder establecer una línea de frontera de acuerdo con las comunidades fronterizas, la Comisión Mixta de Límites tuvo que arbitrar entre ellas y plantear soluciones que satisficieran sus reivindicaciones y pretensiones.

En los siguientes capítulos se va a describir cuales fueron las problemáticas a las que se tuvieron que enfrentar la Comisión Mixta de Límites en Pirineos Centrales, cómo lo hicieron y cuales fueron las soluciones adoptadas.

\section{Conflictividad local en la frontera en Pirineos Centrales}

Las principales cuestiones en esta zona a las que se tuvieron que enfrentar los comisarios de la Comisión Mixta de Límites están relacionadas con el acceso a los pastos de verano en las cabeceras de los valles. Los valles fueron la unidad geográfica, social y económica que articularon la actividad de los asentamientos, los pueblos, a ambos lados de la cordillera. Su principal fuente de subsistencia fue la explotación del medio, entre la que destaca el pastoreo. Su relativo aislamiento y la necesidad de regular el ac-

4. Tratado ajustado entre España y Francia para fijar los límites de ambas naciones en la porción de frontera correspondiente á las provincias de Huesca y Lérida, firmado en Bayona el 14 de abril de 1862. Reproducido en el anexo C10 de Capdevila (2009).

5. Anejos al tratado de límites de 14 de Abril de 1862 entre España y Francia, firmados en Bayona el 27 de febrero de 1863. Reproducido en el anexo C11 de Capdevila (2009). 
ceso a recursos esenciales llevaron a la puesta en práctica de los acuerdos entre valles conocidos comúnmente con el nombre de facerías. Se tiene noticia de estos pactos o tratados desde el siglo XIII (Brunet, 2002) aunque es de suponer que ya entonces se trataba de una práctica habitual. Hasta finales del siglo XVIII las facerías consistieron en complejas instituciones jurídicas que contemplaban, además del acceso a los pastos a caballo entre valles, convenciones sobre cuestiones públicas, de mutuo auxilio, franquicia y protección de las relaciones comerciales, etc. Las facerías sobrevivieron a pesar del desarrollo del Estado moderno, aunque tuvieron que incorporar el beneplácito del monarca para adquirir rango internacional. Con el Estado liberal, que fortaleció su capacidad de acción incluso en los territorios más periféricos, se reconoció la propiedad privada y se estimuló el que todos los bienes pudiesen ser considerados objetos de comercio. Entre sus consecuencias cabe hacer notar la eliminación de todos aquellos acuerdos con carácter perpetuo. A mediados del siglo XIX, las facerías eran vistas desde los gobiernos centrales como prácticas residuales medievales que debían desaparecer o transformarse siguiendo esquemas más modernos (Razquin et al., 2012).

Los principales tratados faceros en la zona que nos ocupa datan de 1513 (abarca entre los valles franceses de Aure y Couserans, y los españoles de Bielsa hasta Arán) y 1514 (Ossau, Aspe y Barétous por parte francesa y desde Tena hasta Ansó por lado español). Ambos fueron una respuesta a la Guerra de Navarra y se interesaron ante todo en mantener la paz entre los valles en caso de guerra entre Francia y Aragón (Poujade, 1998).

Para seguir la pista de los conflictos a los que se tuvieron que enfrentar los comisarios una buena fuente de información son los dos informes que fueron emitidos durante la investigación que llevaron a cabo: se trata de la Memoria presentada por la parte española en la 21 sesión de las reuniones de la Comisión Mixta de Límites, de 31 de marzo de 18596, y la correspondiente Respuesta de los comisarios franceses, de 23 de mayo de $1861^{7}$. En ambos documentos se relacionan, de oeste a este, los diferentes casos: sus protagonistas, sus razones, la documentación existente y las posibles interpretaciones o soluciones. En todos ellos se entremezclan varias categorías relacionadas con el acceso y uso de pastos y bosques: la cuestión de la propiedad, la de la jurisdicción y la de los diferentes derechos de uso y paso. Veamos a continuación, de forma resumida, cuales fueron.

Entre el valle de Ansó, por parte española, y el pueblo de Borce, del valle francés de Aspe, se plantea el uso de pastos en la vertiente septentrional de las montañas de Aspe y Estanés por parte española, y el aprovechamiento de los bosques de Anglus y Espelenguère, compartidos por ambas partes. Según Gorría (1995, 79-80) los de Ansó disponían de suficientes pastos pero no bosques para que los pastores se pudieran pro-

6. AMAEC, Tratados - Negociaciones siglo XIX - no 185-01 (Legajo 64/65-2-1857/1862). Reproducido en el anexo B5 de Capdevila (2009).

7. AMAEC, Tratados - Negociaciones siglo XIX - nº 185-01 (Legajo 64/65-3-1857/1862). Reproducido en el anexo B6 de Capdevila (2009). 
veer de leña y madera para la construcción de sus refugios. Aunque no parece que se cuestione el derecho por parte de los de Ansó a la zona de pastos, si que se puso en duda frecuentemente, por parte de los de Borce, de los derechos esgrimidos sobre los bosques. En algunos momentos, las desavenencias adquirieron tintes trágicos, referidos en la Memoria de 1859 como "asesinatos, robos y rompimientos de paz". En esta historia son los de Borce los que se sienten discriminados y acusan a los de Ansó de invadir terrenos que nos les corresponden y no atender los pactos establecidos. El recorrido histórico de los desencuentros es largo. Ansó argumenta que le corresponde la propiedad de las zonas de pasto en base a una donación realizada en 1234 por parte de Jaume I de Aragón. Sin embargo, no se conserva el documento ni copia fidedigna, de manera que los franceses llegan a poner en duda su existencia. De hecho, no creen que el rey dispusiera de la propiedad de esos terrenos como para poder donarlos, ya que se hallaban en terreno bearnés y no se conoce documento que demuestre su adquisición. Las diferencias entre las comunidades locales obligaron, a mediados del siglo XV, a solicitar un arbitraje al valle vecino de Canfranc que culminó con una sentencial por parte de Juan de Bonsau en la cual se amojonan varios territorios, y se da derecho a los de Ansó para pastar y sacar leña de los bosque a cambio de un pago anual. Algunos términos del acuerdo no quedaron lo suficientemente claros y parece ser que los de Ansó no cumplieron con el pago prometido, lo que llevó a nuevos arbitrajes en 1581 y 1588 para reconocer los amojonamientos, aclarar los derechos respectivos y rescatar el tributo mediante un pago único. Sin embargo, quedó pendiente la cuestión de la jurisdicción, lo cual quedó patente en diferentes litigios derivados de aprehensiones de ganado realizadas por ambas partes. En 1679, en una revisión de la facería, se estableción un reglamento para regular este tipo de capturas. A mediados del siglo XVIII los de Borce pidieron la intercesión de la monarquía francesa reclamando los terrenos hasta la línea de cresta, amparándose en lo dispuesto en el Tratado de los Pirineos. Las reclamaciones fueron atendidas, aunque no resueltas, y posteriormente abandonadas definitivamente tras el Tratado de Basilea de 1795. Las autoridades francesas reprendieron al alcalde y al pueblo de Borce, lo que no les impidió insistir en la cuestión hasta obtener, en 1820, un nuevo acuerdo por el que adquirían el usufructo de la montaña de Estanés a cambio de un pago anual, salvo un año de cada seis. La paz no duró, parece ser que los de Ansó exigieron más cantidad amenazando con romper el acuerdo y volver al estadio anterior. En este punto, los franceses reclamaron a la Comisión Mixta de Límites la posesión efectiva hasta la divisoria de aguas.

Cuestiones similares se daban en el monte vecino de Aspe, donde los de Ansó reclamaban propiedades que eran negadas por los franceses. En un arbitraje de 1535 -contradictorio, por otra parte, con uno de 1507- se determinaba sobre los derechos de uso, dejando claro que no se pretendía resolver ni la propiedad ni la jurisdicción. En el momento del deslinde el asunto continuaba pendiente de esclarecimiento.

Pasado el Puerto de Somport en dirección este, el valle de Canfranc se disputaba con el valle francés de Aspe el acceso a los pastos del Monte Astún, el Monte de la Raca 
y el paraje de La Raqueta. Se trataba de un litigio antiguo, tanto que incluso en los acuerdos de facería de 1514 era considerado como una excepción. Una sentencia de 1524 concedió la propiedad del monte de Astún a Jaca mediante un pago cada dos años. Un acuerdo de 1526 estableció que la propiedad de la Raca y la Raquesta pasaba a ser de Jaca mediante "una prestación anual y perpetua de 130 sueldos jaqueses". En ambos casos, sin embargo, se mantenía la compascuidad, de manera que la parte francesa manda sus ganados a pastar en Astún con la sola condición de no meterlos antes que lo hicieran los de Jaca. Estos últimos tenían también derecho de pasto de día en los bienes comunales de las Neveras y Aguarolas. Los pueblos franceses se quejaron de los problemas que tenían para cobrar de Jaca las cantidades acordadas, lo que les llevó a pedir la intercesión del Consejo de Castilla y el Intendente Real de Aragón. En 1792 se llegó finalmente a un acuerdo de pago que contemplaba los atrasos debidos, haciendo borrón y cuenta nueva, y planteando la reanudación de los pagos periódicos. Pero las guerras de la Convención y de Independencia impidieron que se llevaran a cabo. Se trata, pues, de un litigio sin enfrentamientos en el terreno, pues parecen estar de acuerdo en los derechos y deberes que cada parte asume, pero si existieron incumplimientos que imposibilitaron el cierre de los desacuerdos.

El último punto con historial reciente de conflictos situado en el ámbito de la facería de 1514 fue el protagonizado por el valle de Tena por parte española y el valle de Ossau por parte francesa. Se trata, empero, del caso menos grave (Gorría, 1995, 81). Las relaciones entre ambos valles datan del siglo XIV y el punto de fricción hacía referencia a una compascuidad situada en el Puerto de Jarret, en vertiente francesa, entre el puerto de la Piedra de San Martín y el de Mercadau, que debían compartir el llamado Quiñon de Panticosa (Panticosa, Pueyo y Hoz del Valle del Tena) y los de la Ribera de Saint-Savin. Una sentencia de 1425 lo confirmaba y citaba una carta de paz de 1315. Un concordato de 1593 explicaba con mayor detalle el mecanismo para tratar sobre estos acuerdos: cada dos años, el 1 de julio, una vez en Cauterets y otra en Panticosa, se reunían apoderados de cada parte. Mediante este encuentro se aseguraba la paz entre los participantes y se oían y resolvían los daños y diferencias respecto a lo acordado. También se nombraban cartapaceros, un juez de cada parte que sólo intervenía en el territorio bajo su jurisdicción. En 1618 hubo una sentencia arbitral derivada de disputas en relación a los pastos en el puerto de Jarret que cambió el alcance jurisdiccional de los cartapaceros: el demandante debía dirigirse al cartapacero del territorio contrario. Tras la guerra, en 1818, los españoles reclamaron a los franceses el reintegro sus antiguos derechos de uso compartido.

Más al este se daba el caso que implicaba al valle de Broto por España y al de Barèges por Francia, una relación fuera de las dos grandes facerías de inicios del XVI citadas. Se trataba del disfrute de pastos en lado francés por parte de los de Broto, en la zona conocida como la montaña o los pastos de Usona, situada entre la divisoria de aguas y la población de Gavarnie. El mayor volumen de la cabaña española presionaba para tener ese acceso desde antiguo, lo que la parte francesa planteaba como una es- 
pecie de invasión que, por otro lado, parecía estar consolidada desde por lo menos el siglo XIV, dado que se dispone de una sentencia arbitral de 1390 en la que se declaran comunes entre ambos valles unos determinados territorios. Ello no impidió los desencuentros, tal como demuestran diversos documentos posteriores. Por ejemplo, en 1525 se establece que cada vez que las autoridades se reunan en Asamblea en Gavarnie deben hacer un llamamiento para que "... todo el mundo sin escepcion, debera deponer las armas, y esto á causa de los inconvenientes que puede seguir y se siguen cada dia”. En 1558 se multó a Broto por dos homicidios y se repitieron sentencias y treguas, aunque la conclusión continuó siendo la de que "...se juraban mutuamente la paz en la asamblea de Gavarnia, lo cual no impedia que se disputasen los pastos contenciosos con las armas en la mano". Se sucedieron los pleitos sin llegar a una solución válida para ambas partes: en un convenio de 1744 se llega a concluir que se debe continuar con el status quo imperante, pese a no ser del agrado de nadie y fuente de conflictividad, mientras los monarcas no decidieran otra cosa.

Finalmente queda por abordar lo relacionado con la Val d'Aran, no tanto en su conjunto como peculiaridad fronteriza (Sermet, 1983, 29; Lladonosa, 2001, 42; Capdevila, 2009, 123) sino en lo relacionado con su trazado y la influencia derivada de las relaciones de vecindad locales. Tal como se comenta en la Memoria de 1859, el término jurisdiccional “... por varios parages se desborda sobre las faldas opuestas". Un primer caso comprende las pretensiones del pueblo d'Aubert en la vertiente occidental del Pic de Campsaure y el Tuc de Poilanèr. La presencia del ejército francés con motivo de la guerra de 1793 hizo que perdieran temporalmente el control de los terrenos, pero fue recuperado en 1797 y fueron puestos en arriendo a un vecino de Benasque. Posteriormente fueron despojados de forma violenta por vecinos de Bagneres-de-Luchon, quienes reclamaron la propiedad de esos terrenos hasta la línea de crestas. Durante el siglo XVIII se dieron diferentes sentencias y concordias dando la razón a la parte española, sin embargo a mediados del siglo XIX los terrenos estaban bajo control francés. En el caso de Bossòst, este posee aprovechamientos en vertiente francesa que datan del siglo XV como resultado de diversas adquisiciones y permutas entre vecinos de ambos lados de la cresta. En el lado opuesto, la municipalidad francesa de St-Mamet pretendía exclusividad en esos terrenos. También cabe citar la existencia de terrenos indivisos entre la municipalidad española de Bausen y la francesa de Fos y de derechos de pasto recíprocos entre Canejan por lado español y Fos por lado francés.

\section{Los trabajos de la Comisión Mixta de Límites}

La Comisión Mixta de Límites se constituyó en 1853 en Bayona. Tuvo su primera reunión en noviembre y hasta diciembre de 1858 estuvo ocupada en el deslinde del tramo fronterizo correspondiente al Bidasoa y a Navarra, lo que ocupó veinte sesiones 
formales que se hallan recogidas en los libros de la Comisión ${ }^{8}$. En contraste, el tramo fronterizo de Huesca y Lleida fue resuelto en sólo cuatro sesiones: en marzo de 1859, cuando la parte española presenta su Memoria; en mayo de 1861, en la que los franceses dan su Respuesta; en abril de 1862, en la que se aprueba el proyecto de Tratado y en la de febrero de 1863, en la que se intercambian las cédulas de los delegados que asistieron al amojonamiento y se aprueba el acta adicional al Tratado de 1862. Sin duda, la experiencia adquirida durante los primeros cinco años llevó a una dinámica de trabajo en la cual se limitaron a realizar reuniones formales sólo en los casos necesarios. Es necesario hacer notar, sin embargo, que los comisionados se empezaron a preocupar por este tramo desde mediados de 1857, como veremos más adelante.

La composición de la Comisión Mixta de Límites entre 1857 y 1863 presentó algunas modificaciones en relación con la de 1853. Por parte española, estaban designados como plenipotenciarios el diplomático Francisco María Marín, quien obtuvo el título de marqués de la Frontera por este trabajo, y el mariscal Manuel de Monteverde. Por parte francesa, el principal protagonista fue el general Camille-Antoine Callier quien estuvo acompañado de varios diplomáticos durante la vida de la Comisión. En el tramo que nos ocupa estuvo acompañado por Charles-Victor Lobstein. La Comisión contó, además, con varios responsables de los trabajos de campo: por parte española el teniente coronel Ángel Álvarez de Araujo y el capitán Juan Pacheco y por parte francesa los capitanes Barón Hulot y Bruno Boudet (Sermet, 1983, 3).

Se trató de una Comisión relativamente reducida, a la que se le dotó de amplios poderes para resolver las cuestiones que se plantearan. En palabras del profesor Fernando de Arvizu (1997, 92-93), las funciones de los plenipotenciarios pactadas por ambas partes eran:

" 1 - acordar los medios prácticos que aseguren la tranquilidad en la zona desde el principio de la negociación; para ello, los comisarios recibirían poderes muy extensos, que les permitiesen tomar cualquier medida conservatoria o precautoria y requerir el auxilio de las autoridades civiles y militares.

2 - examinar en profundidad las cuestiones litigiosas a resolver, mediante encuestas e inspecciones locales.

3 - una vez terminada la discusión y decididas de común acuerdo las medidas a tomar, las comunicarían a los Gobiernos respectivos, y serían ejecutivas una vez recibida la aprobación de éstos".

A estas hay que unir, por parte española, las correspondientes instrucciones secretas, que se centraron en evitar las colisiones entre los fronterizos, ajustarse en lo má-

8. Es una serie de cuatro libros que se pueden consultar en AMAEC. Ver tabla 3.6 en Capdevila (2009). 
ximo a Derecho en base a la documentación jurídica presentada por las partes, evitar en lo posible las compensaciones territoriales, buscar un arreglo definitivo en las cuestiones de pastos, estudiar la necesidad de implantar nuevos puestos militares donde convenga y consultar expertos locales de forma discreta "... para no dar la impresión de que consienten que los intereses locales influyan en la negociación".

Hubo, por tanto, un intenso trabajo sobre el terreno, tanto de reconocimiento como de investigación, que implicó desde la mediación en los conflictos locales descritos hasta la gestión del amojonamiento. Una parte importante de este trabajo de campo fue la recopilación de títulos jurídicos y otros documentos de utilidad para averiguar los derechos y deberes de cada parte sobre determinados territorios. La búsqueda se llevó a cabo tanto por archivos gubernamentales como locales. También se procedió, cuando se consideró necesario, a encuestas entre las municipalidades implicadas. Como muestra sirve la titulada Interrogatorio á los valles de Ansó, Echo, Aragües, Aisa, Canfranc, Tena, Broto, Bielsa, Gistain y Benasque remitida mediante escrito de 26 de noviembre de 18579:

"1 - Si el pueblo ó término español tiene derecho á usar de pastos, aguas ó leña en territorio frances, y en este caso designar los parages en q[e]. se tiene el derecho y el pueblo frances á quien pertenecen.

2 - Si este derecho procede de convenios escritos ó verbales ó de uso inmemorial: si es forzoso ó voluntario: en disfrute esclusivo ó en compascuidad: si es perpetuo ó por determinado núm[o]. de años; en toda estacion o en ciertos meses; de dia y de noche ó únicamente de sol á sol: si para toda clase de ganado ó para cierta especie: si se paga algo por remuneracion de pastos y cuanto.

3 - Qué número de cabezas de cada especie disfruta este beneficio.

4 - Si el pueblo español está en pleno uso de su derecho, ó si lo estorban ó contestan los franceses.

5 - Todas las noticias anteriores con respecto á los pueblos franceses q[e]. tengan goce de pastos en el valle español.

6 - Si el término español tiene las yerbas que necesita, ó si por falta de ellas las toma en arrendamiento á otros españoles ó á franceses: si las tienen sobrantes y las dan en arrendamiento y á quien.

7 - Una copia de la escritura última relativa á cada convenio de pastos.

8 - Cualesquiera otros datos ó documentos que puedan servir para esclarecer completamente este asunto".

9. AMAEC, Tratados - Negociaciones siglo XIX - nº 185-01 (Legajos 64/65). 
Una de las razones del éxito de la Comisión Mixta de Límites fue el saber mantener el equilibrio entre las instrucciones recibidas y las presiones por parte de las comunidades locales. Los archivos están repletos de denuncias de "violaciones territoriales" que les hacían llegar tanto las autoridades municipales como otras autoridades gubernamentales: acusaciones de detención ilegal por contrabando, decomisos de leña o de ganado, apropiaciones indebidas de terrenos, etc. En palabras del general Callier (1869): "C'est en étudiant avec soin et loyauté l'origine et les phases diverses des questions, en compulsant les archives, en cherchant le vrai sens des chartes et des différents titres, tout en tenant compte des besoins réels de chacun, que la Commission de 1853 est parvenue à résoudre définitivement tous les litiges”.

La forma de trabajo sobre el terreno la podemos entrever en las instrucciones ${ }^{10}$ que los comisionados españoles hicieron llegar al teniente coronel Álvarez y al capitán Pacheco con motivo de los trabajos en Girona. Se hace especial hincapié en la forma de relacionarse con las autoridades locales. Se les debe hacer saber que se está de su parte pero evitando que se hagan ilusiones precipitadas: “... conviene hacer conocer á los pueblos las circunstancias que les son adversas, así para evitar que se lisongeen infundadamente de que han de obtener lo que tal vez no se logre, como para empeñarlos en buscar con que destruir lo que les perjudique". Siempre que sea posible debe hacerse un croquis de las zonas en entredicho y la documentación obtenida debe ser reconocida por las dos partes "...haciéndoles entender la poca fuerza de las declaraciones y testimonios procedentes de una sola de las partes sin intervencion de la contraria”. Para cada pueblo debe averiguarse si se está de acuerdo con el límite actual y, en caso de desacuerdo, se debe indagar sobre cuales son los límites pretendidos y en base a que lo fundamentan; se debe recopilar y copiar “... asignaciones oficiales de términos, de los catastros, sentencias, convenios celebrados entre los fronterizos, actos de jurisdiccion y cuanto tienda á provar hasta donde se extendía el distrito del pueblo", con preferencia aquellos documentos cercanos a 1660; se deben examinar los argumentos de cada parte y deben documentarse los derechos de los pueblos españoles que se puedan considerar dudosos; se debe averiguar el origen de las señales de límites existentes en los tramos bajo disputa y si la frontera se separa mucho de la establecida en 1660 debe averiguarse la razón. Se hace especial énfasis en todas las cuestiones relacionadas con pastos, el acceso al agua y otras servidumbres adquiridas: "Si el derecho proviene de obligaciones ó contratos escritos ó verbales ó de uso inmemorial: si es perpetuo ó por determinado número de años: en toda estacion ó solo en ciertos meses: de dia y de noche ó únicamente de sol á sol: para toda clase de ganado, ó para determinada especie: si se paga algo por remuneracion de pastos, ó en otro concepto, y cuanto: si es ó no determinado el número de cabezas que disfruta este beneficio; y cualesquiera otras condiciones no previstas aquí".

10. AMAEC. Sèrie Tratados - Negociaciones siglo XIX - nº 221 (Legajo 149-031-1764/1864). 
Con las instrucciones descritas, los agentes de campo debían plantear el trazado a las autoridades locales y recoger su opinión. En el caso de discrepancias, sea por el trazado en si o por desavinencias sobre aprovechamientos en la zona, los agentes debían hacer de intermediarios entre las dos partes para intentar solucionar el problema de la forma más razonable posible. Lo justo y equitable en este caso se reduce a la existencia de una base documental que fundamente los derechos y deberes de cada parte o, en última instancia, a una negociación (ver figura 1). Los agentes de campo de las dos partes pueden colaborar entre si y se mantienen en contacto continuo con los comisarios, quienes les proporcionan instrucciones. Por su parte, los comisarios tambien negocian entre si, sobretodo en forma de discusiones sobre el alcance y validez de los documentos aportados, y se comunican con sus respectivas Secretarías de Estado para informar de las propuestas y recibir instrucciones y soporte político. En muchos casos se puede considerar que la Comisión Mixta de Límites actuó como una especie de tribunal de arbitraje.

Una vez acordado el trazado y codificado en forma de Tratado, los agentes de campo debían establecer la situación y proceder a la construcción de las señales fronterizas. Finalmente, los agentes de campo redactavan una propuesta de acta de amojonamiento que era remitida a los comisarios plenipotenciarios.

Se hecha en falta una representación cartográfica de la línea acordada, de forma similar a las realizadas en deslindes de otras épocas (Capdevila, 2008). El teniente coronel Álvarez de Araujo dibujó la frontera correspondiente al primer Tratado a escala 1:20.000 ${ }^{11}$ pero no continuó con las provincias de Huesca y Lleida. Si se realizó un trabajo cartográfico a escala 1:120.000 por parte española de toda la frontera y que se conserva en dos versiones. Una serie de cinco hojas titulada Territorio fronterizo de Guipuzcoa, Navarra y Bajos Pirineos ${ }^{12}$ y otra de cuatro hojas titulada Linea fronteriza de

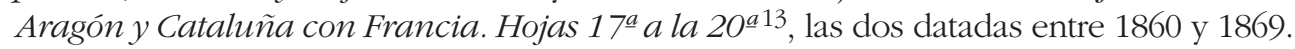

Entre julio y diciembre de 1862 se procedió a la construcción de las señales, repartidas entre mojones sobre la línea de frontera (prisma cuadrado de $50 \mathrm{~cm}$ de base por $75 \mathrm{~cm}$ de alto), mojones para delimitar las zonas de pasto $(30 \mathrm{~cm}$ de base por 40 cm de alto) y, en los lugares donde hubiera piedra viva, cruces y números grabados. Dada la dificultad de acceso a las zonas elegidas, se acordó construir los mojones de mampostería (figura 2) para facilitar el transporte de los materiales. Se usó cemento Portland traído de Bagneres-de-Luchon ya que, en opinión del ingeniero responsable, per-

11. Carta Topográfica de los territorios fronterizos de V Guipuzcoa, Navarra y Bajos Pirineos, con el amojonamiento internacional conforme al Tratado de Limites de 1856, ajustada con Francia por los Excelentísimos señores D. Francisco Marin y D. Manuel Monteverde (1863). Se han hallado dos copias: AMAEC, Planero 01 Cajón 03 Número 03, y en la cartoteca del Centro Geográfico del Ejército, Arm. H Tabla 5 Carp 8 nº 248, Madrid.

12. Una copia en AMAEC, Planero 01 Cajon 03 Número 05, y otra en la cartoteca del Centro Geográfico del Ejército, Arm. H Tabla 4 Carp 7 no230 y 230 bis, Madrid.

13. AMAEC, Planero 01 Cajon 03 Número 04. 


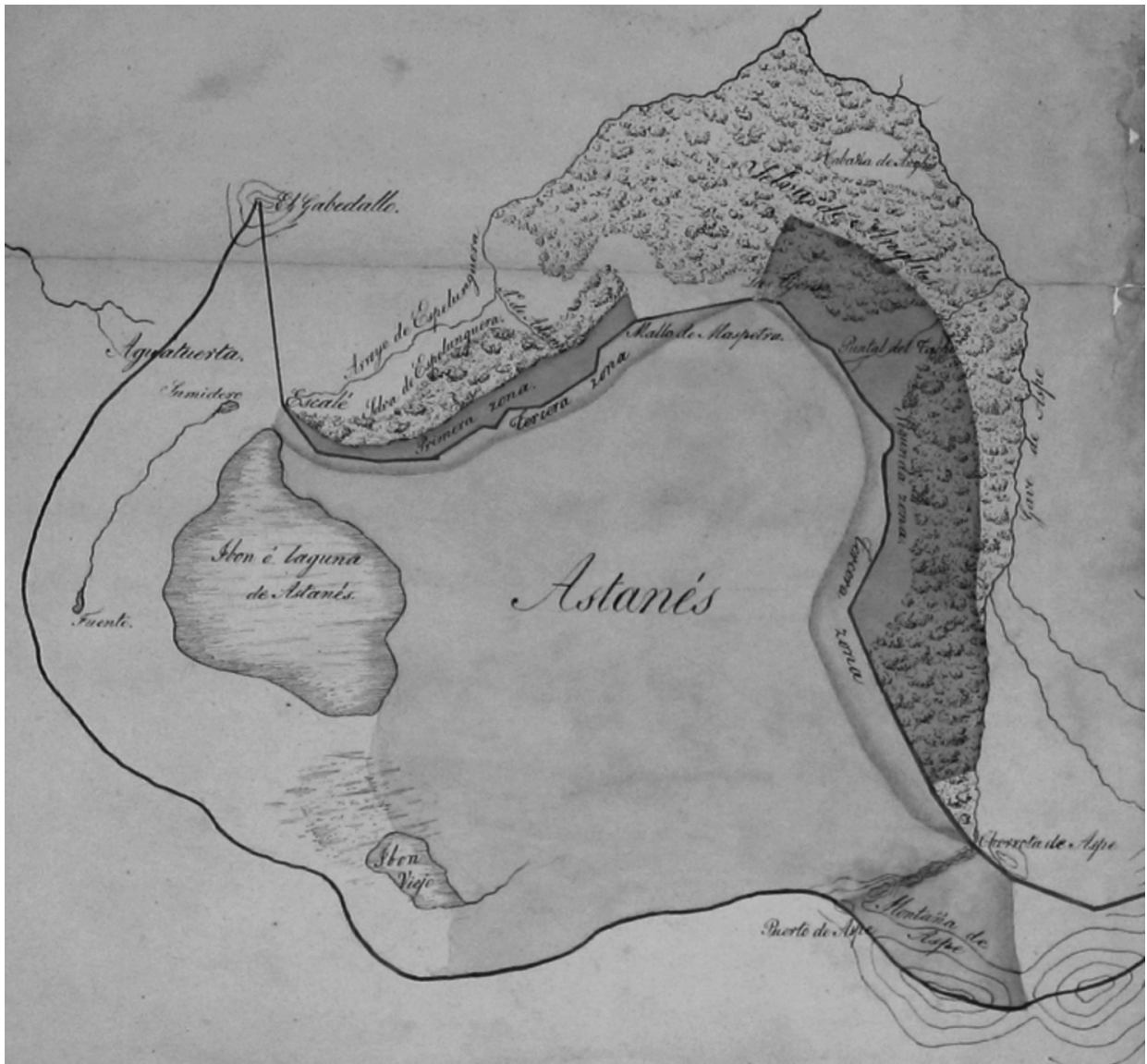

Figura 1. Fragmento del Proyecto de límites de Huesca y Lérica con Francia. 1861. Ejemplo de documento planteado para la negociación. Se dibuja el terreno abarcado por la montaña de Astanés indicando la propuesta de frontera española (línea contínua en rojo superior) y la francesa (la inferior de color verduzco). El norte está en la parte superior.

Fuente: AMAEC, Planero 01 Cajon 02 Numero 11.

mitía afrontar con garantías las inclemencias meteorológicas. El coste del trabajo se desglosa en 96 francos cada mojón grande (77 sobre la frontera), 32 francos el mojón pequeño (27 para delimitar las zonas de pastos) y 20 francos cada cruz grabada ( 77 sobre la frontera y 54 en los pastos $)^{14}$.

14. Rapport de l'Ingénieur des Pont et Chaussées chargé de l'établissement des repéres, 15 de desembre de 1862. AMAEE, Fons Callier - caja 8. 


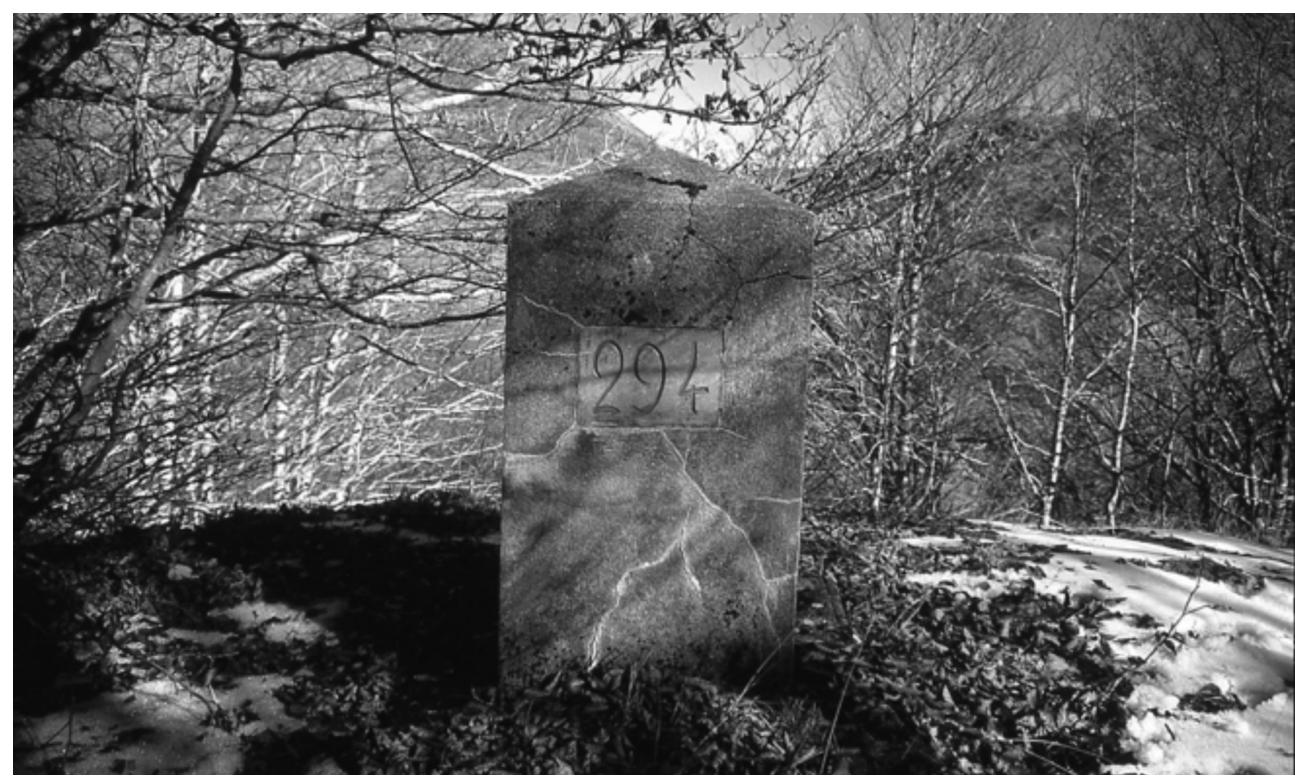

Figura 2. Mojón 294, situado al norte del Paso de Aspe. Es un ejemplo de mojón de mampostería. Fotografía cortesía del matrimonio Darrieu.

\section{Soluciones adoptadas}

Las diferentes disposiciones adoptadas para fijar la frontera y atajar los diferentes puntos conflictivos en su entorno se codificaron en el Tratado de 1862 y sus Anejos de 1863.

En el preámbulo del Tratado ya se apunta la intención con la que se han emprendido los trabajos: se buscan la consolidación de “... la paz y buena armonía entre las poblaciones colindantes de ambos países en la porción de frontera comprendida desde la extremidad oriental de Navarra hasta el valle de Andorra, y terminando de una vez las seculares contiendas que han turbado frecuentemente el orden en algunas partes de esta frontera con notable perjuicio, no sólo de los súbditos de ambos Monarcas, sino tambien de las buenas relaciones entre los dos Gobiernos...".

Algo más del 90\% del trazado de la frontera discurre por las divisorias de aguas ${ }^{15}$. El Tratado de 1862 desarrolla la delimitación con una descripción genérica que luego

15. Dato obtenido a partir del análisis topográfico del trazado de la frontera desarrollado en el anexo A de Capdevila (2009). 
se precisa en el acta de amojonamiento reproducida en los Anejos de 1863, en la que describe la posición de la muga ${ }^{16}$ 273, en el Puerto de Ansó, a la 426, en el Port de Boet.

A partir del artículo 10, el Tratado desarrolla los diversos acuerdos con los que se pretende dar fin a la litigiosidad existente sobre la línea fronteriza. En este mismo artículo se atiende directamente la problemática del aprovechamiento discutido de la montaña de Astanés: los franceses de Borce tienen exclusividad de uso un año de cada seis, mientras que los cinco restantes corresponden a los de Ansó. Por otro lado, tanto los de Borce como los de Ansó comparten el pasto, en la modalidad de día y noche y con derecho al aprovechamiento de madera tanto para cabañas como para el uso cotidiano, en dos fajas de terreno contiguas al Estanés en territorio francés. En el Anejo II de los Anejos de 1863 se describe el trazado y las señales realizadas en esa dos zonas: dos cruces grabadas en el Bois d'Espelunguère (entre las mugas 280 y 286) y doce en el Bois de Sansanet (entre las mugas 287 y 296). Existe una tercera zona en lado español, entre las mugas 285 y 296 , marcada con nueve cruces, en la que "Las reses mayores pertenecientes á Borce, que por cualquier accidente se encontrasen extraviadas en esta tercera zona, podrán ser echadas á territorio francés, pero no estarán sujetas para ello á prendamientos ni multa, siempre que no hayan sido introducidas por los pastores".

En el artículo 11 del Tratado de 1862 se reglamenta el aprovechamiento de los pastos en la vertiente septentrional de la montaña de Aspe. Se aclara que es propiedad de Ansó, quien hará uso de los pastos dos de cada tres años, mientras que el restante será para los del valle de Aspe. No está deslindada en los Anejos de 1863. Aquí los plenipotenciarios acordaron centrar su discusión en torno a las dos sentencias arbitrales del siglo XVI citadas anteriormente y esclarecer los ámbitos abarcados por ellas. Según los franceses, las sentencias sólo afectaban al usufructo mientras que los españoles pretendieron entender en ellas decisiones sobre la propiedad y la jurisdicción. En el Tratado se llega a una solución intermedia: la jurisdicción es francesa, la propiedad española y el usufructo español se lleva a cabo mediante el pago de una renta.

La problemática relacionada con Jaca (montañas de Astun, la Raca y la Raqueta) se regula mediante el artículo 12 estableciendo en cada lugar el tipo de pasto permitido y un pago anual por parte de Jaca.

El artículo 13 reconoce el derecho que tienen algunos vecinos de los valles de Tena y de Ossau de refugiarse en determinados parajes, uno en cada lado de la frontera. Además, en los Anejos de 1863, se definen dos pequeños terrenos compartidos en los alrededores de El Portalet (muga 310), el del lado francés para pastos y el del lado español porque "... se da la sal á los ganados de ambos valles".

16. Voz de origen vasco con la que se denominan tanto los puntos de delimitación de la frontera como las señales que los marcan. Es propia de la frontera hispanofrancesa. 
En la montaña de Jarret se mantiene la costumbre de arriendo de una porción de terreno compartido por españoles y franceses. El artículo 14 establece que se repartirán por igual tanto el producto como las cargas derivadas de esta explotación del terreno. El terreno se señala con tres cruces en los Anejos de 1863. Este acuerdo es loado por las dos partes porque, en su opinión, permite la sustitución de un complejo conjunto de derechos contradictorios entre ellos y que eran uno de los motivos de desavinencias.

El artículo 15 considera como propiedad común de los dos valles vecinos siete quintos de la montaña de Usona (amojonados mediante 26 cruces dobles según descripción en los Anejos de 1863 entre las mugas 315 y 319), que deben darse en arriendo mediante pública subasta. El uso de los pastos de estas zonas se reparte por tiempos entre propietarios y arrendatarios. Aquí se da el caso de que los franceses deben indemnizar a los españoles mediante pago único “... por el abandono perpétuo y voluntario que este hace de todo otro derecho sobre las montañas de las vertientes de Gavarnie...". En los Anejos de 1863 se añade la posibilidad de que los ganados de ambos costados puedan aprovechar las aguas del lago de la Bernatuara.

Del artículo 16 al 22 se regulan las diferentes fuentes de pleitos relacionada con pueblos de la Val d'Aran. Se reconocen propiedades más allá de la frontera mediante la fórmula "...posesión exclusiva y perpétua...". En algunos casos la renuncia de una de las partes es compensada mediante una indemnización en metálico, cuyo cálculo no deja de sorprender: “... que equivalga al capital correspondiente á una renta anual del 3 por 100 consolidado de la Deuda interior de España, igual al rendimiento medio actual de estas propiedades, estimado contradictoriamente por peritos nombrados por uno y otro Gobierno". En otros casos se hace necesario deslindar los terrenos por la diferente forma en que son nombrados por ambas partes: "más como no sean de uso comun entre todos los fronterizos los mismos nombres para designar estas localidades, ni haya conformidad en la mayor ó menor extension territorial á que cada nombre corresponde,..." o por el tipo de pasto que se puede llevar a cabo: "Los ganados de Bo-

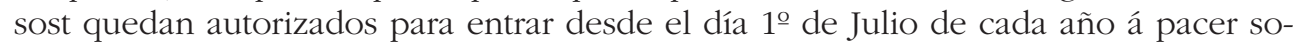
los las segundas yerbas en las montañas francesas de Susartigues y Coradilles". En los Anejos de 1863 se desarrollan diversos amojonamientos relacionados con estos territorios. Por un lado, todos aquellos que se encuentran en el término francés de Bagneres-de-Luchon (entre las mugas 333 y 357), señalados con mojones prismáticos pequeños identificados mediante letras mayúsculas (de la A a la Y, con la excepción de la doble cruz R mostrada en la figura 3), y, por otro lado, diversas zonas compartidas por los vecinos de Bossòst y Montauban (entre las mugas 377 y 378), con algún amojonamiento mediante cruces dobles grabadas e identificadas medainte letras mayúsculas (de la A a la D). En estas zonas también se concretan derechos de paso.

Finalmente, mediante el artículo 23 se plantea la extinción de otros contratos escritos o verbales que no estén contemplados en esta regulación. Si pueden continuar celebrándose contratos de pastos y similares siempre que sean aprobados por el Gobernador Civil y el Prefecto correspondiente y su duración no exceda los cinco años. 


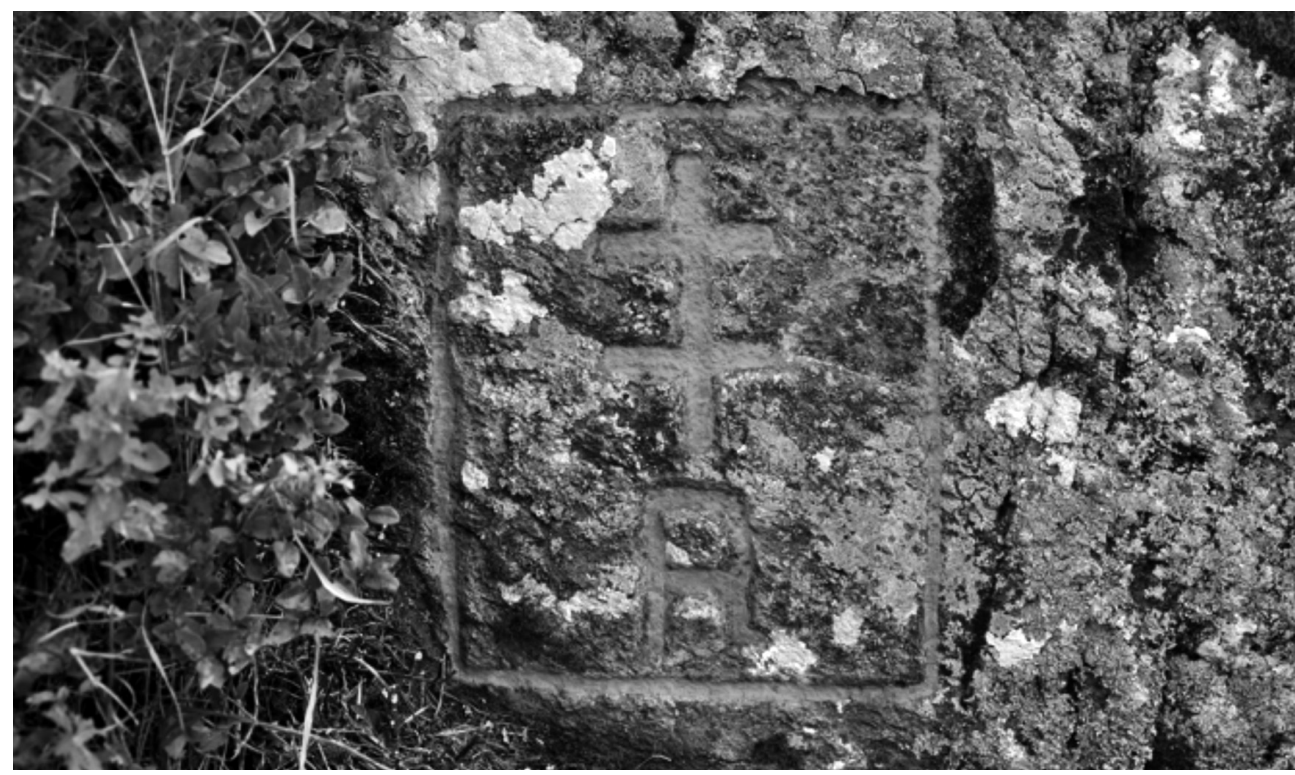

Figura 3. Doble cruz R grabada en roca en la zona situada entre Arres y Bagneres-de-Luchon.

Fotografía cortesía del matrimonio Darrieu.

Del 24 al 26 se estipula los mecanismos de vigilancia (nombramiento de guardias), las reglas para el prendamiento de ganados y la exección de tributación por cruzar la frontera por parte de los rebaños vecinos. En el Anejo III de los Anejos de 1863 se establecen una serie de reglas para los citados prendamientos, desarrollando mejor lo que había quedado fijado en los Anejos al Tratado de Límites de $1856^{17}$.

El artículo 27 anula cualquier otros "convenios, sentencias arbitrales y contratos de cualquier naturaleza bien del trazado de la frontera (...) ó bien á la situacion legal, aprovechamiento y servidumbre de los territorios limitrofes".

\section{Conclusiones}

Entre 1857 y 1863 la Comisión Mixta de Límites llevó a cabo el deslinde de la frontera hispanofrancesa en la parte central de los Pirineos, en las provincias de Huesca y

17. Anejos al Tratado de límites de Bayona de 1856 relativo a la frontera en Guipúzcoa y Navarra, firmados en Bayona el 28 de diciembre de 1858. Reproducido en el anexo C9 de Capdevila (2009). 
Lleida, resultando la definición de una línea de poco más de 300 km., marcada mediante 154 señales sobre el terreno y codificada en un Tratado de 1862 y sus Anejos de 1863. Se trata de la zona más alta del eje de la sierra y la línea transita, en su mayor parte, por la divisoria de aguas. Puede dar la impresión de ser la mera aplicación directa del Tratato de los Pirineos. Sin embargo, de la lectura del articulado de los tratados ajustados se adivina una complejidad que, a priori, no es de esperar. Como se ha visto, los plenipotenciarios tuvieron que enfrentarse y, en muchos casos, arbitrar en los conflictos existentes a caballo de la zona fronteriza entre las comunidades locales de ambos lados. La falta de un deslinde formal tras el Tratado de 1659, junto con la pugna por los recursos naturales en las cabeceras los valles, llevó a una conflictividad de baja intensidad, pero contínua, que no dejaba de ser fuente de acusaciones y violencias que involucraban a las cancillerías de ambos paises. Así pues, se condicionó el deslinde fronterizo a la resolución de esa conflictividad, lo que en términos actuales se consideraría una actuación de ordenación territorial: fijación de propiedades, aclaración de jurisdicciones, reglamentación y reparto de usos, delimitación de zonas, etc. El principal éxito de la Comisión Mixta de Límites fue el de conseguir este gran objetivo para toda la frontera ${ }^{18}$.

Con los Tratados de Límites de Bayona se impone el estado liberal en los más remotos confines del país. De ello es buena muestra el redactado del artículo 13 del primer Tratado ${ }^{19}$, que empieza "En atencion á que las facerías y comunidad en el goce de pastos que, sin término fijo para su duracion, existen entre los fronterizos de uno y otro Estado, han sido muy perjudiciales á su quietud y buena inteligencia, se ha convenido que quedarán por de ningun valor todos los contratos de facería y compascuidad por tiempo indeterminado existentes hoy en virtud de antiguas sentencias ó convenios,...". Sin embargo, esta decisión es matizada, y en buena parte revertida, en los tratados posteriores, como se ha podido observar, donde se permiten algunos de los usos existentes aunque limitándolos en el tiempo y subordinándolos al visto bueno por parte de los representantes estatales en el territorio. La modernidad chocó con las viejas costumbres, de la misma manera que los límites nacionales se entretejieron con la organización espacial existente sobre el territorio y creada por sus habitantes, haciendo buena la famosa frase del historiador Pierre Vilar: "es en las fronteras donde se observa mejor la historia del mundo" 20 .

18. Las soluciones no fueron definitivas en todos los casos, lo que obligó pocos años después, en 1875 , a poner en marcha la Comisión Internacional de los Pirineos (CIP) como instrumento internacional para tratar las problemáticas existentes en torno a la frontera (Sermet 1968).

19. Tratado de límites de Bayona relativo a la frontera en Guipúzcoa y Navarra, firmado el 2 de diciembre de 1856. Reproducido en el anexo C8 de Capdevila (2009).

20. Citada por Sahlins (1993). 


\section{Bibliografía}

Arvizu, F. (1997) La solución institucional del conflicto de los Alduides (Pirineo Navarro). Estudio de las negociaciones entre Francia y España desde 1829 a la conclusión del Tratado de Límites de 1856, según la documentación inédita de los Archivos de los Ministerios de Asuntos Exteriores de Francia y España. León, Universidad de León.

Arvizu, F. (2001) Frontera y fronterizos: el caso de los Alduides (Pirineo de Navarra). Anuario de Historia del Derecho Español, LXXI, 9-48.

Brunet, S. (2002) Les mutations des lies et passeries des Pyrénées, du XIVe au XVIIIe siècle. Annales du Midi: Revue de la France Méridionale, 114 (240), 431-456.

Callier, C.A. (1869) Délimitation de la frontière des Pyrénées. Documents diplomatiques, 11, 43-55.

Capdevila, J. (2008) Mapes i fronteres. El Plano en que se manifiesta la línea de división de los reynos de España y Francia por la parte del Ampurdan y Coll del Pertús de 1764. Treballs de la Societat Catalana de Geografia, 65, 349-360.

Capdevila, J. (2009) Historia del deslinde de la frontera hispano-francesa. Madrid, Centro Nacional de Información Geográfica.

Capdevila, J. (2012) La delimitació de la frontera hispanofrancesa (1659-1868). Tesis. Barcelona, Universitat de Barcelona.

Fernández de Casadevante, C. (1985) La frontera hispano-francesa y las relaciones de vecindad (especial referencia al sector fronterizo del País Vasco). Servicio Editorial Universidad del País Vasco.
Gorría, A.J. (1995) El Pirineo como espacio frontera. Zaragoza, Gobierno de Aragón, Departamento de Presidencia y Relaciones Institucionales.

Lladonosa, J. (2001) Invasions $i$ intents d'integració de la Vall d'Aran a França. Barcelona, Rafael Dalmau, Editor.

Poujade, P. (1998) Les relacions transpirinenques a la Catalunya Moderna: els tractats de "Ligues i Patzeries". Pedralbes: revista d'història moderna, 18 (1), 189-200.

Razquin, M.M., Araguren, E., Taull, M., Fernández, J.A., Ferrer, V., Gascouat, P. y Canals, R.M. (2012) Las facerías internacionales en el Pirineo: historia, actualidad y futuro. En Canals, R.M. y San Emeterio, L. (eds). Nuevos retos de la ganadería extensiva: un agente de conservación en peligro de extinción, Sociedad Española para el Estudio de los Pastos, p. 3-28.

Sahlins, P. (1993) Fronteres $i$ identitats: la formació d'Espanya i França a la Cerdanya, s. XVII-XIX. Vic, Eumo Editorial.

Sermet, J. (1968) El centenario de los tratados de límites y la Comisión Internacional de los Pirineos.

Sermet, J. (1983). La frontière hispano-française des Pyrénées et les conditions de sa délimitation. Lorda, Les Amis du Livre Pyrénéen.

Usunáriz, J.M. (2006) España y sus tratados internacionales: 1516-1700. Pamplona, Ediciones Universidad de Navarra. 
